\title{
DECOMPOSITION OF CERTAIN COMPLETE BIPARTITE GRAPHS INTO PRISMS
}

\author{
DALIBOR FRONCEK \\ University of Minnesota Duluth \\ Duluth, MN 55812-3000 USA \\ e-mail: dalibor@d.umn.edu
}

\begin{abstract}
Häggkvist [6] proved that every 3-regular bipartite graph of order $2 n$ with no component isomorphic to the Heawood graph decomposes the complete bipartite graph $K_{6 n, 6 n}$. In [1] Cichacz and Froncek established a necessary and sufficient condition for the existence of a factorization of the complete bipartite graph $K_{n, n}$ into generalized prisms of order $2 n$. In [2] and [3] Cichacz, Froncek, and Kovar showed decompositions of $K_{3 n / 2,3 n / 2}$ into generalized prisms of order $2 n$. In this paper we prove that $K_{6 n / 5,6 n / 5}$ is decomposable into prisms of order $2 n$ when $n \equiv 0(\bmod 50)$.
\end{abstract}

Keywords: graph decomposition, bipartite labeling.

2010 Mathematics Subject Classification: 05C70, 05C78.

\section{REFERENCES}

[1] S. Cichacz and D. Fronček, Factorization of $K_{n, n}$ into $(0, j)$-prisms, Inform. Process. Lett. 109 (2009) 932-934. doi:10.1016/j.ipl.2009.04.024

[2] S. Cichacz, D. Fronček and P. Kovář, Note on decomposition of $K_{n, n}$ into $(0, j)$ prisms, Lect. Notes in Comput. Sci. 5874 (2009) 125-133. doi:10.1007/978-3-642-10217-2_15

[3] S. Cichacz, D. Fronček and P. Kovář, Decomposition of complete bipartite graphs into generalized prisms, European J. Combin. 34 (2013) 104-110. doi:10.1016/j.ejc.2012.07.018

[4] D. Froncek, Product rosy labeling, Discuss. Math. Graph Theory 28 (2008) 431-440. doi:10.7151/dmgt.1417

[5] R.W. Frucht and J.A. Gallian, Labelling prisms, Ars Combin. 26 (1988) 69-82. 
[6] R. Häggkvist, Decompositions of complete bipartite graphs, Surveys in Combinatorics, 1989 (Norwich, 1989), 115-147, London Math. Soc. Lecture Note Ser. 141 (Cambridge Univ. Press, Cambridge, 1989).

[7] A. Rosa, On certain valuations of the vertices of a graph, in: Theory of Graphs, Internat. Symposium, Rome, July 1966 (Gordon and Breach, N.Y. and Dunod, Paris, 1967) 349-355.

Received 26 January 2015

Revised 13 February 2016

Accepted 13 February 2016 